\title{
MUDANÇAS POLÍTICAS E ELEIÇÕES NA AMÉRICA LATINA ${ }^{1}$
}

Entrevista com Jean-Jacques Kourliandsky

Political changes and elections in Latin America

\author{
Jean-Jacques Kourliandsky ${ }^{2}$ \\ French Institute for International and Strategic Affairs - IRIS
}

\begin{abstract}
RESUMO: Nesta entrevista, o cientista social e especialista em política internacional Jean-Jacques Kourliandsky avalia o cenário político atual da América Latina. Embora na grande maioria dos países latino-americanos, nas últimas décadas, a democracia tenha demonstrado um funcionamento adequado através da conquista dos direitos eleitorais, se observa atualmente um refluxo quanto a esses direitos e ganha força ideias conservadoras e de extrema-direita, que flertam com o autoritarismo. Em resposta ao tema do evento "Discurso e (pós)verdade. Efeitos de real e sentidos da convicção", o pesquisador também relaciona a esse refluxo político a propagação e circulação de inverdades.

Palavras-chave: Democracia; América Latina; Política.
\end{abstract}

ABSTRACT: In this interview, the social scientist and international policy expert Jean-Jacques Kourliandsky assesses the current political landscape in Latin America. Although in the great majority of Latin American countries, in the last decades, democracy has demonstrated its proper functioning through the conquest of electoral rights, there is currently a reflux regarding these rights and conservative and extreme right ideas are gaining strength, which flirt with authoritarianism. In response to the theme of the event "Discourse and (post) truth. Effects of reality and meanings of conviction", the researcher also relates to this political reflux the spread and circulation of untruths.

Keywords: Democracy; Latin-America; Politics.

\footnotetext{
${ }^{1}$ Entrevista realizada no dia 11 de setembro de 2018, durante o V CIAD - Colóquio Internacional de Análise do Discurso: Discurso e (pós)verdade. Efeitos de real e sentidos da convicção. Na ocasião, o entrevistado proferiu a conferência “'A 'verdade' em disputa: o conflito geopolítico entre a Venezuela e a comunidade internacional”. A equipe responsável pela produção, transcrição, retextualização e revisão desta entrevista foi composta por Amanda Gusmão, Fernanda Silva, Júlia Ferreira, Milena França, Franciane Stein Luchini, Julia Trovó e Jhuan Carlos Oliveira Leme, discentes no curso de Bacharelado em Linguística, e Luzmara Curcino, docente no Departamento de Letras e no Programa de Pós-graduação em Linguística da Universidade Federal de São Carlos - UFSCar. Atuaram no apoio técnico à entrevista Maysa Ramos e Rafael Borges Ribeiro dos Santos, discentes do Programa de Pós-graduação em Linguística da UFSCar.

2 Formado em Ciências Políticas pelo Instituto de Estudos Políticos de Bordeaux e Doutor em História Contemporânea pela Universidade de Bordeaux III, é pesquisador do IRIS (Instituto de Relações Internacionais e Estratégicas da França) em questões ibéricas (América Latina e Espanha). Atua como pesquisador e observador internacional junto às fundações Friedrich Ebert e Jean Jaurès. É Membro do Conselho Editorial da Revista Internacional e Estratégica e da Revista Latina. Publica regularmente na Universalia - Anais da América Latina e do Caribe. É autor dos livros Le guide du Costa Rica (2000), La Colombie de A à Z (2011) $e$ Amérique Latine: Insubordinations émergentes (2014).
} 


\section{Cenário Político na América Latina}

Entrevistadores: Em que consiste seu papel de observador internacional das eleições em vários países, em especial os da América Latina, e qual é seu diagnóstico do cenário político atual nessa região?

Jean-Jacques Kourliandsky: Como observador internacional, pude acompanhar processos eleitorais de vários países da América Latina,e neste ano de 2018, as eleições da Colômbia, da Venezuela, do México e do Brasil. Quanto ao cenário político atual da América Latina, o fato de ter havido eleições regulares nas últimas décadas e a possibilidade da presença de observadores internacionais acompanhando esses processos eleitorais, como eu, me levam a interpretar como um sinal da boa saúde do funcionamento democrático nesta região.

A América Latina passou por um longo período histórico sem eleições. Alguns países viveram três décadas de Ditadura Militar, o que hoje já não é mais uma realidade, já que se pode observar a existência de sistemas eleitorais em todos os países dessa região. Entretanto, ao longo dessa conversa, entenderemos que a situação é mais complicada e que não basta apenas ocorrerem eleições para que se possa definir a saúde política de um estado democrático e de uma região específica do mundo, como a América Latina ${ }^{3}$.

\section{América Latina e a virada à direita}

Entrevistadores: Atualmente, essa 'saúde política' parece estar relativamente enfraquecida tendo em vista a ressonância e a ampliação do eco de ideias extremistas, conservadoras de viés autoritário, não apenas no cenário brasileiro, mas de modo geral na América Latina. A seu ver, isso procede e que fatores poderiam ser atribuídos a esse fenômeno?

Jean-Jacques Kourliandsky: De fato, em muitos países da América Latina ocorrem eleições democráticas atualmente, o que não acontecia durante os regimes ditatoriais. Há em média uns trinta anos dessa crise, a Democracia foi reconquistada com muito esforço, e

\footnotetext{
${ }^{3}$ Para uma contextualização desse cenário atual e de acontecimentos históricos que o fundamentam, conferir artigo intitulado "América Latina: território disputado, revelador de liderança internacional", publicado pelo entrevistado nos Anais do V CIAD - Colóquio Internacional de Análise do Discurso, Disponível em: <http://www.ciad.ufscar.br/wp-content/uploads/2020/03/AnaisVCIAD_comISBN_compressed.pdf〉.
} 
testemunhamos a ascensão de governos que poderíamos qualificar como progressistas e de esquerda, como também de nacional populistas.

No entanto, hoje observamos a difusão de ideias extremistas e conservadoras na política na América Latina. Na Argentina, por exemplo, nas eleições de 2015 foi eleito um candidato, que eu não sei bem como defini-lo, por isso diríamos que ele é liberal conservador ${ }^{4}$. Isso também ocorreu no Peru ${ }^{5}$, em 2018, e no Chile ${ }^{6}$, em 2018, por exemplo. No Brasil, por sua vez, em 2016 emergiu uma interpretação golpista da Constituição por parte dos deputados e senadores, o que levou ao processo de impeachment da presidente eleita, Dilma Rousseff ${ }^{7}$.

No que diz respeito ao período democrático, há diferentes e numerosas definições que visam delimitar claramente o momento quando ocorreram as mudanças políticas que se sucederam na América Latina, responsáveis por essa virada à direita. Tudo ocorreu entre os anos de 2000 e 2016. O período dos governos de esquerda na América Latina em geral é caracterizado por dois marcos: em 1999, a vitória de Hugo Chávez na Venezuela, e em 2016, o golpe no Brasil. Passados esses dois acontecimentos, estamos presenciando outro ciclo político. O que nos chama a atenção é o fato de que quando se instaura a Ditadura em um país, o regime se estende para todos os países da América Latina, quando se restabelece a Democracia em um, o mesmo se dá nos demais países, e quando ocorre a ruptura com o modelo progressista, de esquerda, é possível observar o mesmo fenômeno em grande parte desses países. Agora, em quase toda a América Latina, temos governos liberais, neoliberais e conservadores. Como explicar isso?

A primeira explicação é o momento econômico muito distinto, com crises econômicas mundiais que afetaram também a América Latina, como por exemplo, no ano de $2008^{8}$ e depois a nova crise ou pontos de crises a partir dos anos de 2012 e 2013. Tais ocorrências criam condições bastante difíceis para os governos de esquerda que então estavam no poder.

\footnotetext{
${ }^{4}$ Mauricio Macri (Tandil, 8 de fevereiro de 1959), presidente da República Argentina de 2015 a 2019, eleito pela coligação partidária de direita Mudemos.

${ }^{5}$ Martín Vizcarra (Lima, 22 de março de 1963), atual presidente da República do Peru, desde 2018, após a renúncia de Pedro Pablo Kuczynski, eleito em 2016, ambos pelo Partido Peruanos Por el Kambio, de centrodireita.

${ }^{6}$ Miguel Juan Sebastián Piñera Echenique (Santiago, 1 de dezembro de 1949), foi presidente do Chile, de 2010 a 2014, e eleito novamente em 2018, pelo partido de centro-direita Renovación Nacional.

${ }^{7}$ Em 2018, foi eleito à presidência o candidato Jair Bolsonaro, populista, conservador e ultra neoliberal, pelo PSL - Partido Social Liberal, de centro-direita, com amplo apoio da extrema-direita.

${ }^{8}$ Crise financeira de 2008. Em 15 setembro de 2008, marco da crise, um dos bancos de investimentos mais tradicionais dos Estados Unidos, o Lehman Brothers, foi à falência, e as Bolsas do mundo todo despencaram. A data ficou conhecida como segunda-feira negra. Em seguida, outros bancos anunciam perdas bilionárias. Foram meses de muita instabilidade no mercado. Para tentar evitar quebradeiras em série, governos de vários países anunciam planos de socorro à economia, injetando bilhões em bancos.
} 
Isso inviabilizava ou criava condições difíceis para seguir com as políticas sociais que eles vinham aplicando anteriormente, quando a situação econômica e financeira mundial e nacional era de uma relativa bonança. Com a crise de 2008 e seus retornos, grupos das 'elites' econômicas desses países, ou simplesmente aqueles que não fazendo parte desse grupo, do ponto de vista econômico, mas se identificando com as ideias dessas elites, contestaram as políticas sociais, mobilizando-se contra esses governos de esquerda, com a justificativa de que "não pagariam o preço".

As consequências dessa contestação das elites e das medidas que foram adotadas pelos governos frente à crise econômica e a essas contestações recaem mais fortemente nos grupos sociais mais pobres. No Brasil, isso se refletiu em diversos setores, entre aqueles mais imediatamente afetados, como no setor da saúde e da educação, e extensivamente de todos os serviços públicos, afetando até mesmo a cultura. Um exemplo flagrante disto foi o recente incêndio ocorrido, neste ano de 2018, no Museu Nacional do Rio de Janeiro, o que é muito representativo desse momento particular ${ }^{9}$. Entretanto, esse cenário é reversível, como já é passível de observação no México, com a ruptura eleitoral com o governo de centro-direita anterior e a eleição de um candidato de centro-esquerda ${ }^{10}$.

Vamos ver o que ocorre e como se configurará de fato o cenário político na América Latina no ano que vem [2019], quando ocorrerão eleições presidenciais em outros países. Na Argentina e no Uruguai podemos assistir a mudanças significativas e que podem impactar muitos países. Essas mudanças de orientação política nesses países podem propiciar a entrada da América Latina em um novo ciclo político - não sei se tão progressista como o anterior, mas ao menos não tão liberal e conservador quanto atualmente.

\footnotetext{
${ }^{9}$ Entre outros textos de análise do cenário político atual no Brasil, escritos pelo entrevistado, conferir aqueles que se encontram traduzidos e publicados no site do Observatório da Imprensa, a saber:

"O Brasil de Jair Bolsonaro e a diplomacia errática", publicado em 07 de abril de 2020. Disponível em: $<$ http://www.observatoriodaimprensa.com.br/conjuntura-politica/o-brasil-de-jair-bolsonaro-e-a-diplomaciaerratica/>;

"Evangelismo, democracia e reação conservadora na América Latina", publicado em 18 de dezembro de 2019. Disponível em: <http://www.observatoriodaimprensa.com.br/conjuntura-mundial/evangelismo-democracia-ereacao-conservadora-na-america-latina/>;

"O Brasil em distopia democrática", publicado em 30 de abril de 2019 . Disponível em: <http://www.observatoriodaimprensa.com.br/dilemas-contemporaneos/o-brasil-em-distopia-democratica/>.

${ }^{10}$ Andrés Manuel Lopes Obrador (Tepetitán, 13 de abril de 1953), eleito presidente do México, em 2018, pelo partido de esquerda Movimento Regeneração Nacional (Morena).
} 


\section{Novas tecnologias de informação e seu impacto político}

Entrevistadores: Tendo em vista o tema proposto neste V CIAD, "Discurso e (pós)verdade: efeitos de real e sentidos da convicção", no qual o pesquisador fez parte de uma das mesasredondas, que relação pode ser estabelecida entre as novas tecnologias midiáticas de produção e circulação de notícias, seu valor de verdade, e a política eleitoral?

Jean-Jacques Kourliandsky: Essa é uma questão muito interessante. Um exemplo da instrumentalização das novas tecnologias de produção e circulação de notícias, e do efeito da difusão de notícias que não condizem com a verdade factual, é o caso da Venezuela, e o que circula a seu respeito na comunidade internacional ${ }^{11}$. Os países centrais têm difundido notícias, opiniões, informações sobre a situação político-econômica no país que o fazem parecer um risco, um perigo para os demais países, para a Democracia etc. Nos meios de comunicação tradicionais circula amplamente o discurso segundo o qual a Venezuela é representada como um perigo para a paz internacional, comparando-a com países como a Síria, o Iêmen e a Coréia do Norte, por exemplo.

A Venezuela não é um governo que mata seu povo, como o da Síria. Esse país não bombardeia um país vizinho, como a Arábia Saudita e o Iêmen, e também não há armamento atômico como na Coréia do Norte. Por isso, é difícil entender essa situação curiosa. Todos os dias há muita informação e muitas críticas em relação à Venezuela, na mídia internacional. Em geral, essas notícias visam a fomentar uma mudança política, uma troca de governo, mas não se preocupam efetivamente com o povo venezuelano, não apresentam de fato uma solidariedade com essas pessoas, que, de fato, estão passando por um momento social e econômico complicado. Tenho então observado com atenção a situação difícil em que se encontra a Venezuela, as dificuldades enfrentadas por sua população, mas também o modo como essas dificuldades vinham sendo instrumentalizadas para ações distintas por parte dos Estados Unidos, por exemplo, de modo a provocar uma mudança política neste país, não em benefício do povo, mas em função de seus interesses estratégicos na região ${ }^{12}$.

\footnotetext{
${ }^{11}$ A esse respeito, cf. o artigo intitulado "A 'verdade' em disputa: o conflito geopolítico entre a Venezuela e a comunidade internacional", deste mesmo autor, e que será publicado em breve no livro organizado com as conferências do V CIAD, pela EdUFSCar.

${ }^{12}$ A esse respeito, cf. entre outros, o texto publicado no site da Fundação Jean-Jaurés, intitulado "Venezuela: réflexions sur l'élection présidentielle". Disponível em: <https://jean-jaures.org/nos-productions/venezuelareflexions-sur-l-election-presidentielle>.
} 
Recebido em: 12 de fevereiro de 2020.

Aceito em: 17 de abril de 2020. 